Check for updates

Cite this: RSC Adv., 2017, 7, 43780

Received 19th July 2017

Accepted 24th August 2017

DOI: 10.1039/c7ra07945a

rsc.li/rsc-advances

\section{Porous high specific surface area-activated carbon with co-doping N, S and P for high-performance supercapacitors $\dagger$}

\begin{abstract}
Mengjiao Xu, Danyang Li, Yan Yan, Teng Guo, Huan Pang ${ }^{\text {D * }}$ and Huaiguo Xue*
Starting from the renewable biomass material palm kernel shell (PKS), nitrogen, sulfur and phosphorus codoped high specific surface area porous activated carbon materials were prepared through carbonization and $\mathrm{KOH}$ chemical activation and applied to the supercapacitor electrode materials. PKS is a low-cost carbon source byproduct of biomass, which is rich in cellulose, lignin, and moisture, and its other components also provide nitrogen, sulfur, phosphorus and other heteroatoms for the final product. After further activation with different ratios of alkali and carbon, porous activated carbon (PAC) with different pore sizes could be obtained. The presence of heteroatoms not only provides redox pseudocapacitance, but doping heteroatoms is also beneficial to suppress irreversible changes of the oxygen-containing functional groups on the carbon material surface during the charging and discharging process. In $3 \mathrm{~mol} \mathrm{~L}^{-1} \mathrm{KOH}$ electrolyte solution, PAC showed an excellent electrochemical performance with good cycling stability, and its maximum specific capacity could reach $380 \mathrm{~F} \mathrm{~g}^{-1}$.
\end{abstract}

\section{Introduction}

Traditionally, activated carbon (AC) is a commercially functional material that is available from petroleum coke, bitumen and coal. ${ }^{1-3}$ At present, AC has attracted a lot of industrial applications, including electrochemical supercapacitors (SCs), lithium-ion batteries, hydrogen storage, catalysts, adsorbents, and medical components. ${ }^{4-10}$ Its production process is simple, and hence it is widely used in various fields. For electric double layer capacitor (EDLC) applications, AC exhibits a great demand for due to the advantages of high conductivity, chemical stability and low cost. The AC electrodes, through the accumulation of electrostatic charges at the electrode-electrolyte interface, store the charges and do not involve any chemical charge during the charging and discharging process, which is the basis of EDLC. ${ }^{\mathbf{1 1 - 1 6}}$ Moreover, the specific capacitance of the AC-based SCs can be enhanced by the incorporation of heteroatoms (e.g., nitrogen, oxygen, sulfur, phosphorus, etc.) into the carbon framework, which is also directly proportional to the specific surface area of the PAC. ${ }^{\mathbf{1 7 - 2 1}}$

Because raw materials from coal, asphalt and coke that are used for the preparation of $\mathrm{AC}$ are not renewable and are expensive, research is now focused on finding low-cost, resource-rich and renewable natural biomass carbon sources

School of Chemistry and Chemical Engineering, Yangzhou University, Yangzhou, 225002, Jiangsu, China.E-mail: huanpangchem@hotmail.com; panghuan@yzu.edu. cn; chhgxue@yzu.edu.cn

† Electronic supplementary information (ESI) available. See DOI: 10.1039/c7ra07945a (including hemp, ${ }^{22}$ fungus mushroom, ${ }^{23}$ pine cone, ${ }^{24}$ litchi shells, ${ }^{25}$ pumpkin, ${ }^{26}$ coconut shells ${ }^{27}$ and bamboo $^{28}$ ) to produce $\mathrm{AC}$, which is a very promising candidate as the SCs electrode. Palm Kernel Shell (PKS) as a dry solid waste, is produced after the extraction of palm oil. ${ }^{29-36}$ Because of the abundance of PKS, the recovery of value-added products is highly desirable. Therefore, the research and application of PKS' basic performance have been paid great attention to since it proves to be a promising material for the production of AC. ${ }^{33-36}$ The biggest challenge in PKS processing is the carbon activation process, which is a key factor that will have a direct impact on the performance of AC. For developing vast pore networks in carbon materials, various biomass-derived ACs are typically developed using physical activation ${ }^{37,38}$ (e.g. $\mathrm{O}_{2}, \mathrm{CO}_{2}$ or steam) or chemical activation $^{39-41}$ techniques (e.g. $\mathrm{KOH}, \mathrm{H}_{3} \mathrm{PO}_{4}, \mathrm{ZnCl}_{2}$, etc.) for EDLC applications. Among them, potassium hydroxide $(\mathrm{KOH})$, because of its better activation effect, has become a widely used activator since it can promote the activated carbon to create a larger specific surface area and stronger adsorption performance. ${ }^{\mathbf{4 2 - 4 4}}$

Recent studies have shown that the surface chemical properties of activated carbon materials are the primary factors that affect the specific capacitance of supercapacitors. A large number of biomass materials are being studied for supercapacitors, particularly after conducting carbonization and activation processes. The main advantages based on the PKS research method are that: (1) the nature of the discarded biomass material of PKS. ${ }^{29-32}$ PKS, as biomass precursors with a carbon content of more than $60 \%$ by weight, can be easily dispersed in the $\mathrm{KOH}$ aqueous solution and its sizes can reach 
nanoscale. Unique natural composites are generally complexes of organic chain macromolecules, including various ionic groups such as carboxylic acids, phenols and alcohols. If used in the preparation of porous carbon materials, cheap and environment friendly carbon precursors have a rich production effect, which can further optimize the pore structure and improve its capacitance performance. (2) A variety of functional groups and heteroatoms for doping (including $\mathrm{N}, \mathrm{S}, \mathrm{O}$ and $\mathrm{P}$ ) could be formed. ${ }^{17-21}$ By a series of effective methods of carbonization and activation, PKS can not only form a carbon structure and provide more active sites to promote the formation of porous structures, but also improve the capacitance performance of porous carbon electrode material. Thus, PKS has a crucial effect on the preparation of porous activated carbon materials and their application in supercapacitors for improved capacitance.

However, the nature of carbon from the biomass will vary significantly, and hence it is a challenge to optimize the raw materials required for the process. Obviously, the pore microstructure and element composition of AC depends on the carbon source used or the activation parameters including the ratio of alkali to carbon and activation temperature. Here, by two steps of carbonization and subsequent $\mathrm{KOH}$ activation, it was mainly studied on the properties of activated carbon prepared by PKS and the performance effects applied to EDLC. The specific capacitance of $380 \mathrm{~F} \mathrm{~g}^{-1}$ could be achieved via the EDLC electrode based on PAC. Furthermore, electrochemical studies have shown that AC electrodes have satisfactory chargedischarge cycling stability to realize ultra-high power/energy density for EDLC, which is much higher than that achieved by various other biomass-derived $\mathrm{AC}$ electrodes. The specific capacitance $\left(C_{\mathrm{s}}\right)$ of the electrode materials prepared from similar activation methods of the various biomass precursors reported in the literature is summarized in Table 1 for comparison with our results. Based on the results obtained, it could be inferred that the excellent performance of biomassderived porous activated carbon would make it the most attractive tool for high performance supercapacitors and low cost energy storage devices.

\section{Experimental}

\section{Synthesis of the PKS-derived activated carbon}

The waste PKSs were purchased from an online marketplace. First, to remove soil, dirt and surface impurities, we washed the PKSs thoroughly with clean water and repeatedly with distilled water, and then crushed them into pieces, followed by drying at $100{ }^{\circ} \mathrm{C}$ in an oven. For pre-carbonization, the dried PKSs were pyrolyzed at $500{ }^{\circ} \mathrm{C}$ in a vacuum tube furnace for $2 \mathrm{~h}$ under nitrogen atmosphere to remove the small amount of organic molecules. Subsequently, for improving the specific surface area by chemical activation, the pre-carbonated PKSs were dipped in $\mathrm{KOH}$ aqueous solution as the chemical activating agent with a weight ratio of $1: 4$ and then stirred thoroughly for $6 \mathrm{~h}$ to ensure complete infiltration. Thereafter, the mixture was annealed at $900{ }^{\circ} \mathrm{C}$ for $1 \mathrm{~h}$ under $\mathrm{N}_{2}$ atmosphere. Finally, hydrochloric acid $(\mathrm{HCl}, 1 \mathrm{M})$ was used to wash the annealed sample repeatedly, followed by rinsing with excess of distilled water to obtaining a neutral $\mathrm{pH}$. The final sample was obtained by drying at $80^{\circ} \mathrm{C}$ in air and labeled as porous activated carbon (PAC). Fig. 1 shows the transformation of PKSs into porous activated carbons.

In contrast, the product prepared without the addition of $\mathrm{KOH}$ using the same procedure was labeled as nonporous activated carbon (NAC).

\section{Material characterizations}

The crystal structure was measured by a Bruker D8 Advanced $\mathrm{X}$-ray diffractometer (Germany, CuK $\alpha$ radiation: $\lambda=1.5416 \AA$ ) to

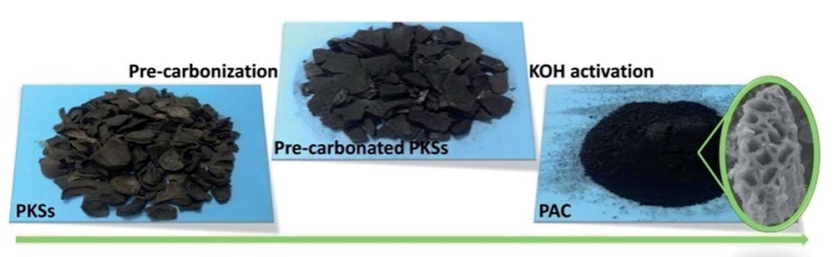

Fig. 1 Schematic for the synthesis of porous activated carbons from PKSs.

Table 1 Comparison of specific capacitance $\left(C_{s}\right)$ of electrodes from different biomass precursors

\begin{tabular}{|c|c|c|c|c|c|c|}
\hline Lotus seedpods & $\mathrm{KOH}$ & 1813 & 402 & 0.5 & $6 \mathrm{M} \mathrm{KOH}$ & 11 \\
\hline Rotten potatoes & $\mathrm{KOH}$ & 960 & 269 & 1 & $6 \mathrm{M} \mathrm{KOH}$ & 13 \\
\hline Prawn shells & $\mathrm{KOH}$ & 1917 & 357 & 0.5 & $6 \mathrm{M} \mathrm{KOH}$ & 17 \\
\hline Tobacco rods & $\mathrm{KOH}$ & 2115 & 286.6 & 0.5 & $6 \mathrm{M} \mathrm{KOH}$ & 18 \\
\hline Coconut leaves & $\mathrm{CO}_{2}$ & 492 & 133.4 & 0.2 & $6 \mathrm{M} \mathrm{KOH}$ & 37 \\
\hline Particleboards & $\mathrm{KOH}$ & 1758 & 263 & 0.05 & $7 \mathrm{M} \mathrm{KOH}$ & 44 \\
\hline Cabbage leaves & $\mathrm{KOH}$ & 3102 & 336 & 1 & $6 \mathrm{M} \mathrm{KOH}$ & 45 \\
\hline Shiitakes & $\mathrm{KOH}$ & 2335 & 315 & 0.5 & $6 \mathrm{M} \mathrm{KOH}$ & 47 \\
\hline Oil palm kernel shells & $\mathrm{KOH}$ & 727.3 & 210 & 0.5 & $1 \mathrm{M} \mathrm{KOH}$ & 49 \\
\hline Popcorn & $\mathrm{KOH}$ & 1489 & 245 & 0.5 & $6 \mathrm{M} \mathrm{KOH}$ & 50 \\
\hline
\end{tabular}


analyze X-ray diffraction (XRD) patterns. The functional groups investigation and the chemical analysis of the samples were carried out using a Spectrum One (Perkin Elmer, USA) FTIR spectrometer and an Omicron NanoTechnology (ESCAL.ab250) $\mathrm{X}$-ray photoelectron spectrometer, respectively. The morphologies of the prepared porous structure were characterized via field emission scanning electron microscopy (FESEM, ZeissSupra 55) and high resolution transmission electron microscopy (HRTEM, Tecnai G2 F30 S-TWIN) with energy dispersive X-ray spectroscopy (EDS) mapping, while the $\mathrm{N}_{2}$ adsorptiondesorption isotherm and Brunauer-Emmett-Teller (BET) specific surface area of the samples were obtained at $77 \mathrm{~K}$ using an ASAP 2020 (Micromeritics, USA) apparatus. Thermal properties were determined using the PerkinElmer Pyris 1 thermogravimetric analyzer (TGA, USA), where the sample was heated to $500{ }^{\circ} \mathrm{C}$ at a heating rate of $5{ }^{\circ} \mathrm{C} \mathrm{min}^{-1}$ under $\mathrm{N}_{2}$ flow. The Raman analysis of the samples was recorded using a DXRxi Raman spectrometer (Thermofisher, USA) with the laser power set at $1.5 \mathrm{~mW}$ to minimize the heating effect.

\section{Fabrication of working electrodes}

In the electrochemical performance characterization, the working electrodes were fabricated for the mixture with a mass ratio of $8: 1: 1$ of the dried AC, conductive carbon (Super P) and polytetrafluoroethylene (PTFE) binder in $N$-methylpyrrolidinone (NMP) solvent dispersant, followed by thorough stirring for $0.5 \mathrm{~h}$ using the agate mortar till a paste was obtained. This paste was uniformly coated onto a pre-cleaned nickel foam substrate with a square size of $1 \mathrm{~cm} \times 1 \mathrm{~cm}$. Then, the electrode coated with abovementioned fabricated paste was annealed at $80{ }^{\circ} \mathrm{C}$ for $12 \mathrm{~h}$ in an oven. Until the annealed electrode was cooled to room temperature, we used a hydraulic equipment at $10 \mathrm{MPa}$ to press the final electrode to allow sufficient contact of the foam nickel with the active materials. The mass of the active substance was obtained according to the ratio for calculating the electrochemical properties of the materials.

\section{Electrochemical measurements}

To examine the electrochemical properties of the prepared electrodes, we conducted cyclic voltammetry (CV), galvanostatic charge-discharge cycling (CDC) and electrochemical impedance spectroscopy (EIS) analysis, which were carried out using a conventional three-electrode configuration on a $\mathrm{CHI} 760 \mathrm{D}$ electrochemical workstation (Shanghai Chenhua, China) under the premises in a potential range of $-1.0-0.0 \mathrm{~V}$. Herein, the performance of the prepared electrodes was measured by placing them in $3 \mathrm{M} \mathrm{KOH}$ electrolyte. The electrochemical workstation was equipped with a counter electrode (platinum), a reference electrode $(\mathrm{Hg} / \mathrm{HgO})$ and a working electrode just above the prepared AC electrode. Cyclic voltammetry and galvanostatic CDC were obtained at different scan rates of 5-100 $\mathrm{mV} \mathrm{s}^{-1}$ and various current densities in the range 1-20 A g ${ }^{-1}$, respectively. EIS plots reveal the response of the EDLC electrode observed in the frequency range from $0.1 \mathrm{~Hz}$ to $10^{5} \mathrm{~Hz}$.

\section{Results and discussion}

Fig. 2 exhibits the representative XRD patterns of PAC and NAC samples. Two intense and broad diffraction peaks are evidently generated at approximately $2 \theta=24^{\circ}$ and $44^{\circ}$ of both of the PAC and NAC samples, corresponding to the (002) and (100) diffraction patterns of amorphous carbon structure, respectively. The intensity of the graphitic carbon structure at $2 \theta=24^{\circ}$ is reduced and further broadened upon carbonation and activation. A wider peak indicates that the carbon structure is amorphous due to the increase in distance between activated carbon and carbon atoms and the destruction of the graphite structure during carbonation and activation. A wide diffraction peak at $2 \theta=44^{\circ}$ indicates that PAC sample has a certain degree of graphitization, which facilitates the conductivity of AC. ${ }^{45}$ The higher diffraction intensity of the activated PKS at a lower $2 \theta$ value clearly indicates that $\mathrm{AC}$ has a porous structure.

Generally, we adopt the FTIR spectra to qualitatively analyze the surface functional groups of AC, and both infrared spectra patterns of AC samples before and after activation are observed to be nearly similar (Fig. S1 $\dagger$ ). The formation of the flexural vibration at $3415 \mathrm{~cm}^{-1}$ and $3700 \mathrm{~cm}^{-1}$ and bending vibration at $1560 \mathrm{~cm}^{-1}$ corresponding to $-\mathrm{O}-\mathrm{H}$ stretching are attributed to physical adsorption of water molecules or hydroxyl groups domination. The two peaks that belong to asymmetric and symmetric $\mathrm{C}-\mathrm{H}$ stretching are located at $2924 \mathrm{~cm}^{-1}$ and $2848 \mathrm{~cm}^{-1}$, respectively, while that of the $\mathrm{C}-\mathrm{H}$ group with the deformation mode is located at $1382 \mathrm{~cm}^{-1}$. The carbonyl group on the AC creates two types of weak peaks, separately designated as the stretching mode of $\mathrm{C}=\mathrm{O}$ at $1728 \mathrm{~cm}^{-1}$ and the stretching mode of $\mathrm{C}=\mathrm{C}$ at $1560 \mathrm{~cm}^{-1}$. Simultaneously, it is clearly observed that the $\mathrm{C}-\mathrm{O}-\mathrm{C}$ stretching mode is located at $1070 \mathrm{~cm}^{-1}$. Compared with NAC, the absorption peak of PAC shifted to a higher wavenumber due to $\mathrm{KOH}$ activation. From the FTIR analysis, it is observed that PAC and NAC exhibit an amorphous carbon structure with large amounts of oxygencontaining functional groups, the presence of which could provide additional pseudocapacitance and good conductivity. The numerous carboxyl and hydroxyl groups on AC surfaces also indicate the excellent capacitance properties of the material.

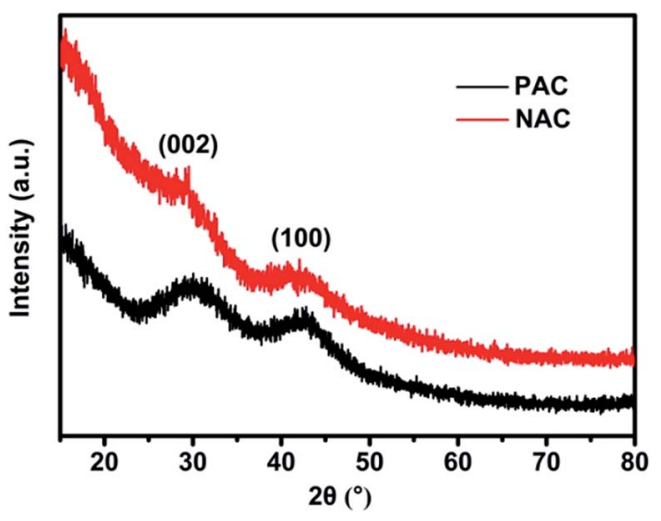

Fig. 2 XRD patterns of PAC and NAC. 
The PKS comprises organic macromolecules such as cellulose, hemicelluloses and lignin, which can absorb a large amount of elements from the soil during the growth process, including $\mathrm{C}, \mathrm{H}, \mathrm{O}, \mathrm{N}, \mathrm{S}, \mathrm{P}, \mathrm{K}, \mathrm{Na}$, and $\mathrm{Mg}$. Most likely, these elements, in the form of inorganic matter, as the most important source of ash, still remain in the PKS carbonized material because of the pyrolysis in nitrogen environments. Presence of these elements is also observed during carbonization in nitrogen atmosphere. Therefore, it is highly probable that a large amount of $\mathrm{N}, \mathrm{S}, \mathrm{P}$ elements are introduced into the final carbon material during $\mathrm{KOH}$ activation.

The surface element composition of heteroatoms for PAC and NAC including carbon, nitrogen, oxygen, sulfur and phosphorus, which are clearly detected at $285 \mathrm{eV}, 405 \mathrm{eV}, 532 \mathrm{eV}$, $164 \mathrm{eV}$ and $133 \mathrm{eV}$ respectively, was analyzed using XPS (Fig. S2 $\dagger$ ). The amounts of different elements on the surface of the materials as calculated by XPS analysis are listed in Table 2, which show the content of N, S, P to be similar in NAC and PAC samples (the content of N, S, P for PAC only slightly higher than NAC). Furthermore, the central spectra of resolved peaks at $\mathrm{N}$ $1 s, S 2 p$ and P 2p for PAC are shown in Fig. 3. It is distinct that contents of nitrogen, sulfur and phosphorus elements of the prepared carbon material are low. In case of PAC, $\mathrm{N}$ doping accounts for $1.71 \%$ (atomic percentage), $S$ doping accounts for $0.76 \%$ and $\mathrm{P}$ doping accounts for $0.57 \%$. As presented in Fig. $3 \mathrm{a}$, three peaks of the XPS spectrum for $\mathrm{N} 1 \mathrm{~s}$ could be detected as pyridinic $\mathrm{N} 1(398.48 \mathrm{eV})$, pyrrolic $\mathrm{N} 2(400.48 \mathrm{eV})$ and pyridine- $\mathrm{N}$ oxide N3 $(403.08 \mathrm{eV})$. These $\mathrm{N}$ species produced may not only promote the formation of various nitrogen-containing functional groups on the porous carbon surface, but also can contribute to the efficient utilization of synergistic effect of heteroatoms and the rapid absorption for dissolved substances, thus enhancing cycling stability. ${ }^{46}$ Furthermore from Fig. $3 \mathrm{~b}$, the $\mathrm{S} 2 \mathrm{p}$ can be decomposed into two adjacent peaks between $168 \mathrm{eV}$ and $170 \mathrm{eV}$, corresponding to some possible forms of the oxidation states arising from the strong interaction of sulfur and oxygen, which may be due to the sulfur element on the carbon surface adjacent to the oxygen molecules caused by oxidation. ${ }^{47}$ Finally, as observed in Fig. $3 \mathrm{c}$, two peaks located at $134.48 \mathrm{eV}$ and $133.48 \mathrm{eV}$ are separated from P 2p. This occurs due to the possible phosphorus-oxygen functional groups, namely phosphates or $\mathrm{C}_{-} \mathrm{PO}_{3}$ phosphorus groups, which can moderately restrict irreversible reaction during discharge/ charge process. Therefore, it can be inferred that the persistence of phosphorus in AC may contribute to the improvement of its electrochemical performances. Hence, a typical N, S, P codoped activated carbon material is conducive to the formation of AC surface functionalities for EDLC effect in the charge storage mechanism.

Table 2 Detailed XPS analysis of the samples

Surface elemental compositions of samples

\begin{tabular}{llllll}
\hline Samples & C (at\%) & O (at\%) & N (at\%) & S (at\%) & P (at\%) \\
\hline NAC & 87.12 & 10.01 & 1.69 & 0.65 & 0.53 \\
PAC & 89.04 & 7.92 & 1.71 & 0.76 & 0.57
\end{tabular}

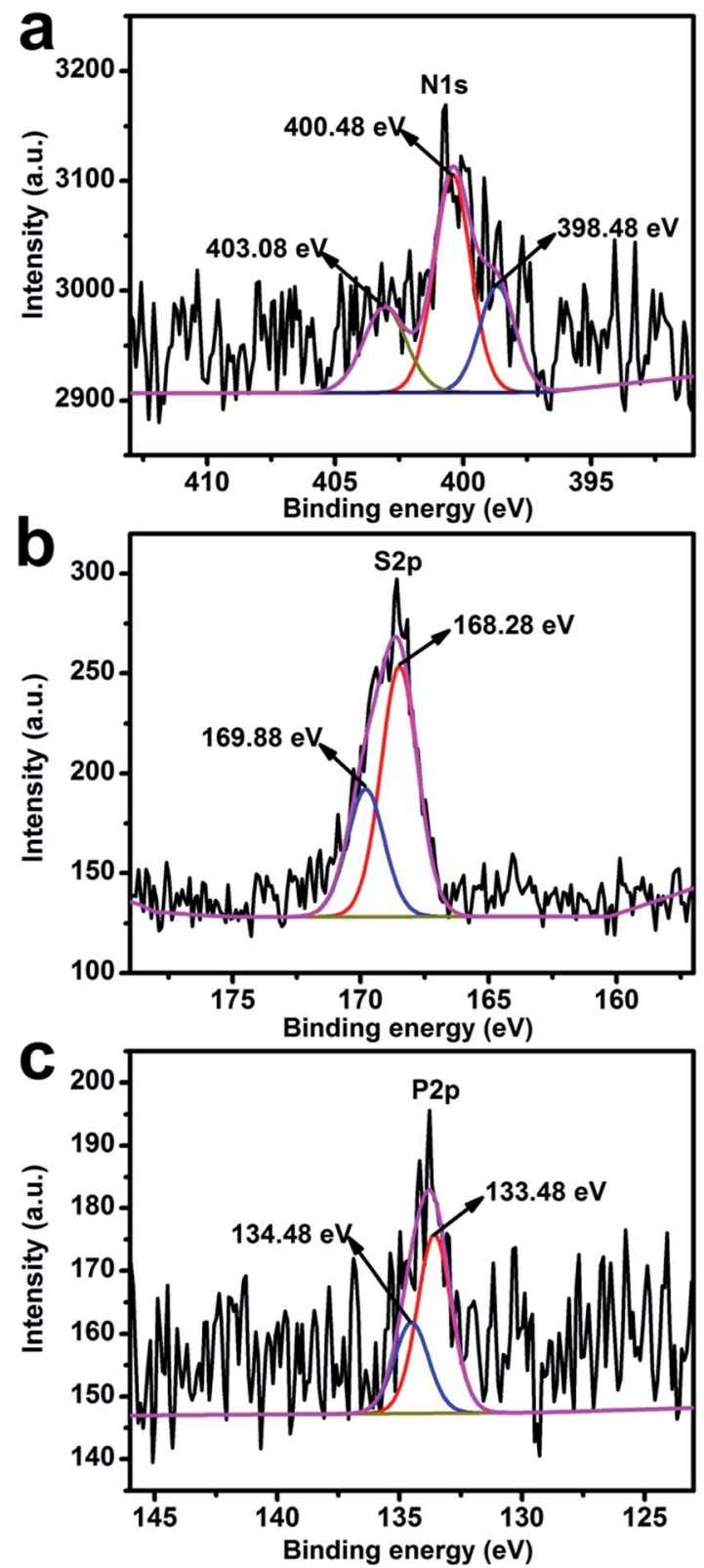

Fig. 3 XPS spectra of (a) N 1s, (b) S $2 p$ and (c) P $2 p$ regions for PAC, respectively.

In the case of pyrolysis, the decomposition of lignocellulose in PKS and the volatilization of some organic matter are carried out to obtain AC with a porous structure. Fig. S3c $\dagger$ is a SEM image of the PKS carbonized material obtained after carbonization at $500{ }^{\circ} \mathrm{C}$. Fig. S3a and S3b $\dagger$ shows a SEM image of the NAC and PAC prepared from PKS carbonized material. A developed and irregular porous structure appeared in the PAC after $\mathrm{KOH}$ activation. After increasing the magnification, we could clearly see the surface of the AC inside the large holes with a large number of mesopores and micropores, as displayed in Fig. S3d; $†$ hence in is confirmed that the material for the porous structure shows irregular block structures. It is taken for granted that the activation agent $(\mathrm{KOH})$ scattered into the layered 
porous structure could sufficiently facilitate activation. NAC was found to exhibit only a few pores.

As for the $\mathrm{KOH}$ activation, the carbon framework containing various potassium compounds is partially etched by the carbon activation reaction between $\mathrm{KOH}$ and the feedstock. Consequently, the carbon lattice expands and the formed metal (K) can be effectively embedded in the carbon lattice of the carbon matrix, while the production of $\mathrm{H}_{2} \mathrm{O}$ and $\mathrm{CO}_{2}$ also contributes to the formation of a well-formed pore network in the resulting product during the activating process. Moreover, after washing to remove the resulting potassium salts and excess $\mathrm{KOH}$, the pores that were present at the etched location could not be restored to their previous construction, thus resulting in a large number of PAC with high porosity.

As is depicted in Fig. 4, high-resolution TEM images of AC surface conditions exhibited almost similar morphologies, including the homologous five elemental mapping images of carbon, oxygen, nitrogen, sulfur and phosphorus for PAC. It is clear from the figure that there are numerous micropores and mesopores in AC, and the transparent and blank spots in the figure represent the pores of AC with pore size ranging from several nanometers to dozens of nanometers. As a result, the PAC material exhibits a larger specific surface area and a higher porosity. In addition, the sample is essentially made up of amorphous components with partially curved graphitized layers. In contrast, the NAC sample merely exerts the porous framework structure with only a few blank spots. Moreover, EDX spectra and the inset figures in Fig. S4† show detailed EDX elemental analysis of the PAC samples. It is clear from Fig. $\mathrm{S} 4 \dagger$ that the contents of $\mathrm{N}, \mathrm{S}, \mathrm{P}$ measured by EDX mapping in the PAC after $\mathrm{KOH}$ activation are not significantly different from those for PAC summarized in Table 2 using XPS method, but slightly higher than the contents of N, S, P in the NAC observed using XPS method. Therefore, the higher N, S, P contents after the $\mathrm{KOH}$ treatment are conducive to the improvement of the supercapacitor performance.

The carbonized material without activation has a small amount of large pores and has a loose surface. This macroporous structure facilitates the rapid entry of the activator

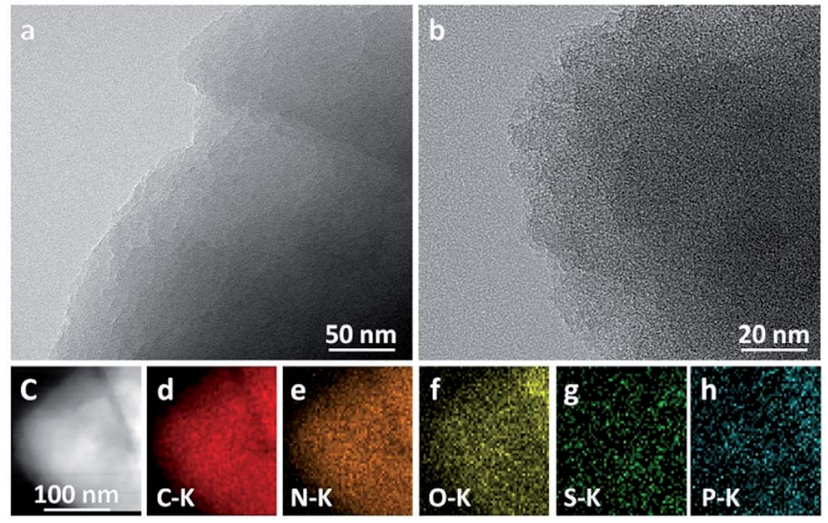

Fig. 4 High resolution TEM images of (a) PAC and (b) NAC; STEM image (c) and the corresponding EDS mapping of $\mathrm{C}-\mathrm{K}$ (d), $\mathrm{N}-\mathrm{K}$ (e), $\mathrm{O}-\mathrm{K}(\mathrm{f}), \mathrm{S}-\mathrm{K}(\mathrm{g})$ and $\mathrm{P}-\mathrm{K}(\mathrm{h})$ from PAC.
$(\mathrm{KOH})$ into the activated pores, thus leading to the formation of ultra-high specific surface area. Moreover, large porous structure with large pore volume of the carbonized material enables the activator to etch with the carbon atoms faster for poreformation and shorten the time of the activation reaction. This also indicates that the activation time has a minor effect on activated carbon. The formation of tunnels and pores during activation can facilitate ion adsorption and transportation in the charge storage mechanism, which makes the ion diffusion in the supercapacitor electrolyte much easier. Therefore, the porous surface (Fig. 4) indicates that PAC activated by $\mathrm{KOH}$ may achieve an ultra-high specific surface area and a large pore volume. This leads to a high specific capacitance, which is consistent with the nitrogen adsorption and desorption curve of the material.

Both curves of the nitrogen adsorption-desorption and pore size distributions for PAC and NAC measured at $77 \mathrm{~K}$ are shown in Fig. 5. It shows that the microporous structure of the $\mathrm{N}_{2}$ absorption increased greatly at $P / P_{0}<0.4$. When $P / P_{0}>0.4$, there is an evident hysteresis loop growing slowly for PAC. The emergence of this phenomenon indicates that PAC is composed of a large number of micropores and mesopores, in line with the combination of type I and IV isotherms. ${ }^{48}$ PAC consists of micropores (less than $2 \mathrm{~nm}$ ), mesopores ( $2 \mathrm{~nm}$ to $50 \mathrm{~nm}$ ) and macropores (greater than $50 \mathrm{~nm}$ ), with the mesopores dominant in the sample. The specific surface area and pore volume of PAC are primarily as high as $2760 \mathrm{~m}^{2} \mathrm{~g}^{-1}$ and $1.6 \mathrm{~cm}^{3} \mathrm{~g}^{-1}$, respectively. At the same time, the pore size distribution is centered at $2.3 \mathrm{~nm}$. On the contrary, NAC has a specific surface area of $1124 \mathrm{~m}^{2} \mathrm{~g}^{-1}$ and a pore volume $0.5 \mathrm{~cm}^{3} \mathrm{~g}^{-1}$; its pore size distribution is centered at $1.9 \mathrm{~nm}$. The high specific surface area indicates that PAC has higher specific capacitance. Considering the comparative data above, it is easier to conclude that PKS
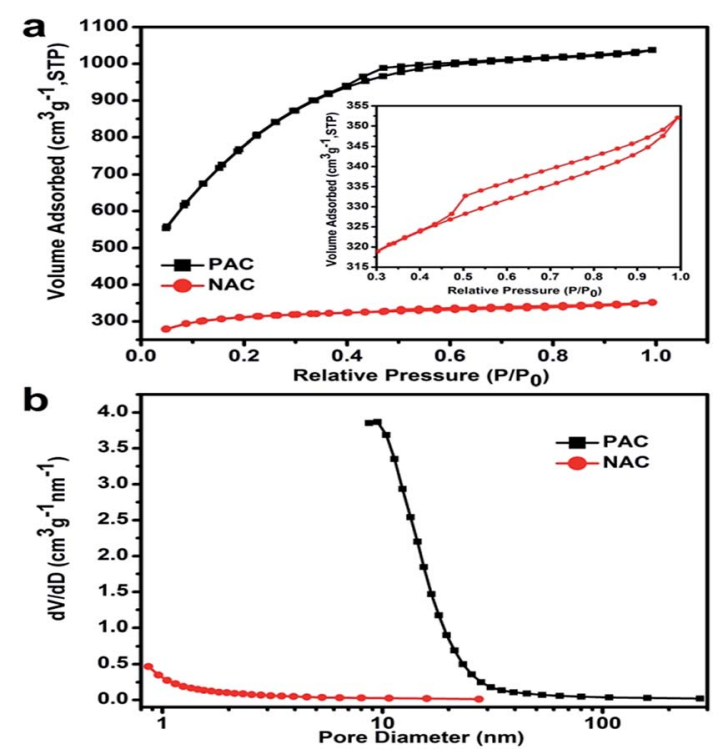

Fig. 5 (a) Nitrogen adsorption-desorption isotherms and (b) BJH pore size distributions of PAC and NAC. The inset in (a) shows the partial enlargement of nitrogen adsorption-desorption isotherms of NAC. 
precursors with $\mathrm{KOH}$ activation at high temperature could be obtained rapidly and produced ultra-high specific surface area and appropriate mesopore size, which is beneficial for efficient charge storage. The pore-rich surface and narrower pore size distribution of AC provide high ion accessibility through wider transport channels to micropores. Therefore, we expect that PAC would be a promising electroactive material for advanced SCs.

To further investigate characteristics of PAC, Raman analysis and thermal properties, which were adopted to quantify the amount of AC that occurred during the heating of PKS, were performed, and the results obtained are shown in Fig. S5 and $\mathrm{S} 6, \uparrow$ respectively. Clearly, as depicted in the Fig. S5, $\uparrow$ the two prominent peaks shown in the Raman spectrum are located at $1342 \mathrm{~cm}^{-1}$ and $1587 \mathrm{~cm}^{-1}$, individually corresponding to $\mathrm{D}$ (defects and disorder)-band and $\mathrm{G}$ (graphitic)-band, which is attributed to the $\mathrm{C}-\mathrm{C}$ graphitic lattice vibration mode. Because of the incorporation of heteroatom $\mathrm{N}, \mathrm{S}$ and $\mathrm{P}$ in the PAC framework, some amount of disorder is caused that partially makes the G-band stronger. $I_{\mathrm{D}} / I_{\mathrm{G}}$, known as the ratio of intensities of "D-band" to "G-band", is calculated to be about 0.88 and 0.95 for PAC and NAC, respectively, which could explain the higher graphitization degree with large amount of structurally ordered graphite crystallites for PAC. Furthermore, on observing the TG and DTG curves, three distinct decomposition periods of PAC, which occurred within the broad range of $200-900{ }^{\circ} \mathrm{C}$, show different thermal degradation behaviors. It is essential for the degradation trend of PAC to compare with the one of lignocellulosic biomass; the weight loss primarily at $300-700{ }^{\circ} \mathrm{C}$ was probably due to the degradation of hemicelluloses $\left(200-260^{\circ} \mathrm{C}\right)$, cellulose $\left(240-350^{\circ} \mathrm{C}\right)$ and lignin (above $380^{\circ} \mathrm{C}$ ). In view of the TGA analysis data, $500^{\circ} \mathrm{C}$ is optimized as the minimum pyrolysis temperature of PKS. Considering that the activation temperature plays an important role in regulating the electrochemical and textural properties of PKS derived activated carbons, a series of experiments were carried out to select the optimum activation temperature reaction conditions. In this study, the electrochemical and textural properties of synthetic porous activated carbons were quantitatively estimated by measuring their specific capacitance $\left(C_{\mathrm{s}}\right)$, BET SSA and pore volume. The figures of BET and $C_{\mathrm{s}}$ at different temperatures are listed in Table S1. $\dagger$ It could be clearly observed from the images that the excellent capacitive properties of PKS at $900{ }^{\circ} \mathrm{C}$ could be attributed to their relatively high BET SSA, optimum pore volume and the surface properties mentioned above.

To evaluate the electrochemical capacitance behavior of the PAC and NAC supercapacitor electrodes prepared above, the CV analysis was performed to probe in $3 \mathrm{M} \mathrm{KOH}$ solution, and the voltage window was -1.0 to $0.0 \mathrm{~V}$. Both $\mathrm{CV}$ curves for PAC and NAC at a scan rate from 10 to $150 \mathrm{mV} \mathrm{s}^{-1}$ are depicted in Fig. 6a and b, respectively. Fig. $6 c$ shows the comparison of CV curve for PAC and NAC at a scanning rate of $10 \mathrm{mV} \mathrm{s}^{-1}$, indicating that PAC activated with $\mathrm{KOH}$ has a good capacitance performance. As the activated carbon is composed of micropores, mesopores and macropores in the channel structure, the electrolyte ions penetrating into the pores of different sizes need to overcome
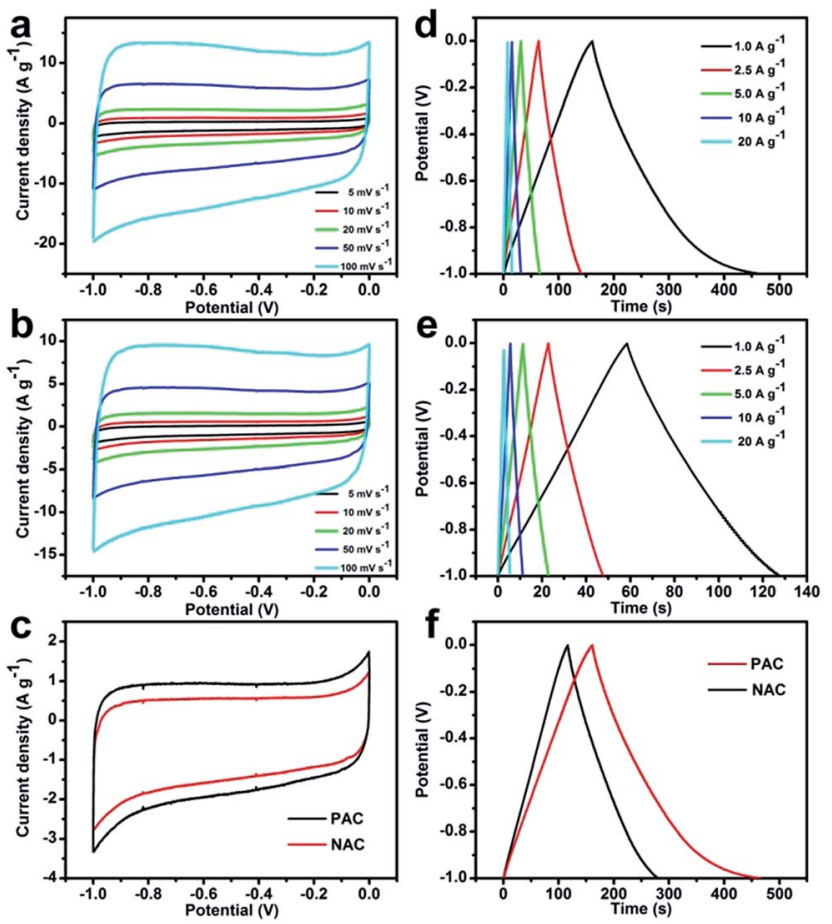

Fig. $6 \mathrm{CV}$ curves of (a) PAC and (b) NAC within the $-0.1-0.0 \mathrm{~V}$ range at a scan rate from 10 to $150 \mathrm{mV} \mathrm{s}^{-1}$ in $3 \mathrm{M} \mathrm{KOH}$; comparison of (c) CV curves for PAC and NAC at scan rate $10 \mathrm{mV} \mathrm{s}^{-1}$; CDC curves for (d) PAC and (e) NAC at various current densities of 1.0-10.0 $\mathrm{A} \mathrm{g}^{-1}$ and (f) the area chart for CDC behavior of PAC and NAC electrodes in $3 \mathrm{M} \mathrm{KOH}$ electrolyte at $1.0 \mathrm{~A} \mathrm{~g}^{-1}$.

different resistance. Due to the resistance, electrolyte ions have slower diffusion rate in the micropores compared to the macropores, so the response current may produce a certain relaxation time. Therefore, EDLC cyclic voltammetry curves show a quasi-rectangular shape, which indicates that the material with porous structure is stable. At the same time, it is further observed that the response current and the quasi-rectangular area of the CV curve for the PAC electrode, as compared with NAC, are much larger. In addition, in the range of the scan voltage, there is a slight polarization at the positive and negative potentials, which represent the complex reversible redox reactions occuring on the AC surface. The presence of polarization phenomenon is also attributed to the multiple functional groups on the AC surface.

Galvanostatic CDC cycling method is commonly used for studying the capacitance performance of electrode materials. Fig. 6d and e show galvanostatic CDC curves for PAC and NAC placed in $3 \mathrm{M} \mathrm{KOH}$ electrolyte at various current densities of 1.0-10.0 A g ${ }^{-1}$, respectively. Fig. 6f shows the comparison of the CDC behavior of PAC and NAC electrodes at $1 \mathrm{~A} \mathrm{~g}^{-1}$ current density, concluding that the charging and discharging time of PAC is significantly longer than that of NAC. The galvanostatic CDC curves of AC show a good linearity and a relatively symmetrical triangular shape, indicating that $\mathrm{AC}$ has a good EDLC behavior with excellent reversibility.

According to the following formula, we could calculate the specific capacitance of AC: 


$$
C=\frac{I t}{m U}
$$

where $C, I, m, U$ represent the specific capacitance of the material, the measured current density, the mass of the active material and the charge and discharge voltage range, respectively. As shown in Fig. 7a, the maximum specific capacitance of PAC at the current density of $1.0 \mathrm{~A} \mathrm{~g}^{-1}$ is about $380 \mathrm{~F} \mathrm{~g}^{-1}$, while the non-activated NAC has a maximum specific capacitance $102 \mathrm{~F} \mathrm{~g}^{-1}$, both of which are derived from the discharging curves, indicating that the specific capacitance of the activated PAC electrode compared with NAC is much higher. When the current density is increased 20 times $\left(20 \mathrm{~A} \mathrm{~g}^{-1}\right)$, the ions do not have enough time to diffuse into all the pore structures of the electrode material, resulting in a decrease in the capacitance with the increase in the current density. The capacitance is still retained at $52 \%$, which demonstrates that PAC has a rapid charge and discharge capability and excellent discharge rate performance due to the high specific surface area, large pore volume and nanoporous structure. The micropores favorably exhibit a dense double layer capacitance, and the mesoporous and macroporous structures can facilitate the rapid diffusion and transfer of electrolyte ions in the pores, while for NAC with smaller pores it is difficult to exhibit a dense double layer capacitance. Furthermore, the surface oxygen-containing functional groups of the active components are likely to exist as part of the pseudocapacitor.
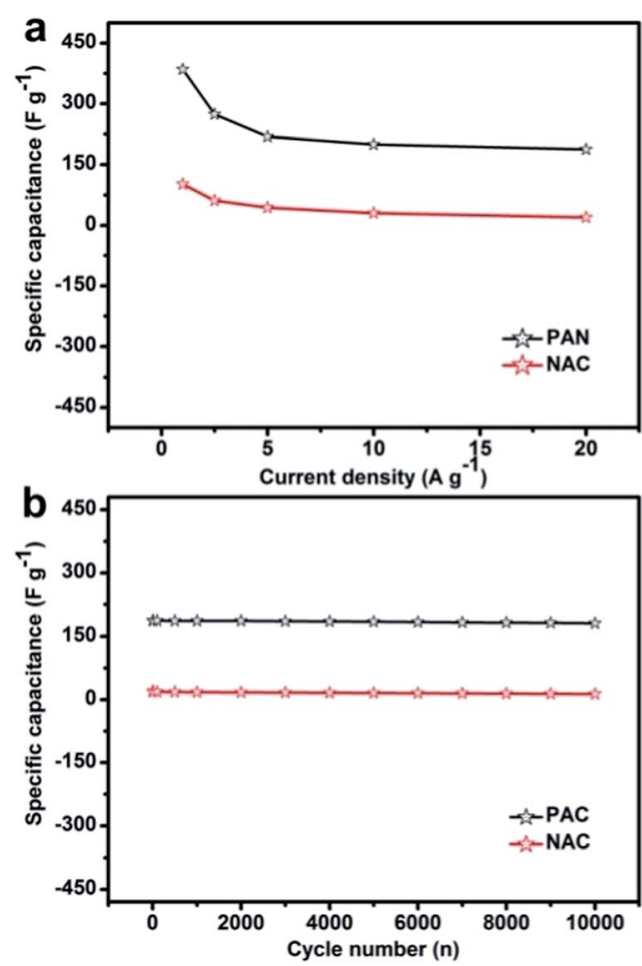

Fig. 7 (a) Specific capacitance of PAC and NAC electrode derived from the discharging curves at various current densities of 1.0-20.0 $\mathrm{A} \mathrm{g}^{-1}$ and (b) the charge-discharge cycling stability test of PAC electrode at $1 \mathrm{~A} \mathrm{~g}^{-1}$.
Studies have shown that PKS as a byproduct of biomass, not only is a low-cost carbon source, but also its rich cellulose, lignin, moisture and other major components provide nitrogen, sulfur, phosphorus and other heteroatoms for the final product. Due to the synergistic effect of the presence of various heteroatoms such as $\mathrm{C}, \mathrm{N}, \mathrm{O}, \mathrm{S}$, and $\mathrm{P}$, the carbon material prepared exhibits larger pseudocapacitance. Moreover, heteroatom doping is beneficial to suppress an irreversible change of the oxygen-containing functional groups on AC surface during the charging and discharging process. It also shows that the reasonable porosity generated by $\mathrm{KOH}$ activation of $\mathrm{AC}$ is beneficial for the formation of dense double electric layer capacitance and rapid transmission in $\mathrm{KOH}$ electrolyte, which can significantly improve the capacitance behavior. ${ }^{49}$

Another important indicator for enhanced performance of supercapacitors is electrochemical stability. To check the actual expandability of these electrodes, a porous activated carbon was used, and a current density of $1 \mathrm{~A} \mathrm{~g}^{-1}$ was applied with a $3 \mathrm{M}$ $\mathrm{KOH}$ electrolyte to perform 1000 cycles of the electrochemical stability; the result obtained is shown in Fig. 7b. The capacitance drops slowly in the first 500 cycles due to the reduction of the extra pseudocapacitance, which is caused by the gradual disappearance of the surface oxygen-containing functional groups of the porous activated carbon after the chemical activation. For 10000 cycles, the capacitance remained stable and the final specific capacitance retention rate was about $96 \%$, which indicates that PAC has excellent cycle stability as an ideal EDLC electrode material.

The study of the ion transport mechanism and further demonstration of the performance for PAC and NAC electrodes were testified using electrochemical impedance spectroscopy. The EIS analysis carried out in the frequency range from $10 \mathrm{mHz}$ to $10^{5} \mathrm{~Hz}$ shows the Nyquist plot with a small semicircle and a nearly straight line at the high/low frequency region, respectively (Fig. 8), intuitively indicating porous carbon electrodes with a distinct capacitive property. From data analysis of the high frequency region, a small semicircle is generated relevant to charge transport phenomena $\left(R_{\mathrm{CT}}\right)$ during the testing process at the electrode-electrolyte interface. Herein, the electrolyte ions could rapidly diffuse to the outer surface of

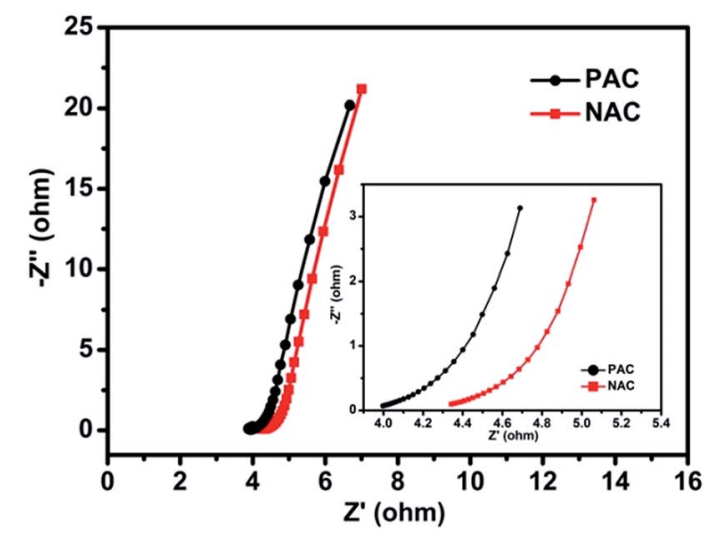

Fig. 8 Nyquist plots of PAC and NAC electrodes. 
the activated carbon electrode and the inner surface of the macropores or mesopores, thus concluding that there is an existence of Faraday impedance of charge transfer. Moreover, the ohmic resistance $\left(R_{\mathrm{S}}\right)$ was estimated from which it could be deemed that the internal resistance of the carbon material is very small (less than $0.5 \Omega$ ), indicating that the carbon material is well conductive. ${ }^{50}$ It also manifested that the kinetics process of the electrochemical system is rapid and the ion transport plays a leading role. Viewing from the low frequency region where the inclined portion of the impedance rises sharply (slope close to $90^{\circ}$ ). The straight line shows that AC materials exhibit pure double electric layer capacitance behavior and the characteristics of rapid electrolyte ion transfer. The fundamental reason for this capacitive behavior is that the palm kernel shell-based porous activated carbon has a porous structure with low resistance, and thus is suitable for ion diffusion.

\section{Conclusions}

In conclusion, $\mathrm{N}, \mathrm{S}$ and $\mathrm{P}$ co-doped PAC was successfully prepared via pyrolysis and successive $\mathrm{KOH}$ activation using palm kernel shell as raw material. The specific surface area of activated PAC is about $2760 \mathrm{~m}^{2} \mathrm{~g}^{-1}$, which could be favorable to improve its EDLC applications. Along with the synergistic effect of $\mathrm{N}, \mathrm{P}, \mathrm{S}$ and other types of elements doping, the prepared carbon material exhibited excellent electrochemical capacitance characteristics. Furthermore, the presence of carbonyl and hydroxyl functional groups on PAC surface also provided the extra pseudocapacitance. In the $3 \mathrm{M} \mathrm{KOH}$ electrolyte, the specific capacitance is as high as $380 \mathrm{~F} \mathrm{~g}^{-1}$ at a current density of $1 \mathrm{~A} \mathrm{~g}^{-1}$. Subsequently, PAC shows excellent cycle performance. After 10000 charge and discharge cycles, the specific capacitance is still maintained at $96 \%$. In this study, a variety of heteroatom-doped carbon materials was successfully prepared using biomass. The carbon material prepared showed a high specific surface area and exhibited excellent electrochemical properties. Therefore, the palm kernel shell is an excellent raw material for production of activated carbon.

\section{Conflicts of interest}

There are no conflicts to declare.

\section{Acknowledgements}

The acknowledgements come at the end of an article after the conclusions and before the notes and references. This study was supported by the Program for New Century Excellent Talents of the University in China (NCET-13-0645) and the National Natural Science Foundation of China (NSFC-21201010, 21671170 and 21673203), Innovation Scientists and Technicians Troop Construction Projects of Henan Province (164200510018), Program for Innovative Research Team (in Science and Technology) in University of Henan Province (14IRTSTHN004), the Six Talent Plan (2015-XCL-030), and Qinglan Project. We also acknowledge the Priority Academic Program Development of Jiangsu Higher Education Institutions and the technical support we received at the Testing Center of Yangzhou University.

\section{Notes and references}

1 Y. Z. Ma, B. J. Yu, Y. Guo and C. Y. Wang, J. Solid State Electrochem., 2016, 20, 2231-2240.

2 Q. X. Xie, S. W. Zhou, A. R. Zheng, C. Xie, C. Y. Yin, S. H. Wu, Y. F. Zhang and P. Zhao, Electrochim. Acta, 2016, 189, 22-31.

3 X. J. Wei, X. Q. Jiang, J. S. Wei and S. Y. Gao, Chem. Mater., 2016, 28, 445-458.

4 Q. Jiang, Z. H. Zhang, S. Y. Yin, Z. P. Guo, S. Q. Wang and C. Q. Feng, Appl. Surf. Sci., 2016, 379, 73-82.

5 H. L. Wang, W. H. Yu, J. Shi, N. Mao, S. G. Chen and W. Liu, Electrochim. Acta, 2016, 188, 103-110.

6 A. Jain, R. Balasubramanian and M. P. Srinivasan, Chem. Eng. J., 2016, 283, 789-805.

7 S. Y. Zhu, Y. Q. Wang, J. C. Jiang, X. Yan, D. Sun, Y. C. Jin, C. W. Nan, H. Munakata and K. Kanamura, ACS Appl. Mater. Interfaces, 2016, 8, 17253-17259.

8 D. L. Sivadas, S. Vijayan, R. Rajeev, K. N. Ninan and K. Prabhakaran, Carbon, 2016, 109, 7-18.

9 M. Zhou, F. Lu, X. S. Shen, W. W. Xia, H. He and X. H. Zeng, J. Mater. Chem. A, 2015, 3, 21201-21210.

10 L. Fan, L. Tang, H. F. Gong, Z. H. Yao and R. Guo, J. Mater. Chem., 2012, 22, 16376-16381.

11 B. Liu, X. H. Zhou, H. B. Chen, Y. J. Liu and H. M. Li, Electrochim. Acta, 2016, 208, 55-63.

12 W. C. Li, Y. Ding, W. Q. Zhang, Y. Shu, L. Zhang, F. C. Yang and Y. H. Shen, J. Taiwan Inst. Chem. Eng., 2016, 64, 166-172.

13 Y. X. Huang, L. L. Peng, Y. Liu, G. J. Zhao, J. Y. Chen and G. H. Yu, ACS Appl. Mater. Interfaces, 2016, 8, 15205-15215.

14 S. Q. Zhu, Q. L. Chen, Y. Y. Shi, Z. Y. Chen, R. Q. Bao, L. Zhou, L. R. Hou, K. N. Hui and C. Z. Yuan, J. Solid State Electrochem., 2016, 20, 713-723.

15 B. Li, M. B. Zheng, H. G. Xue and H. Pang, Inorg. Chem. Front., 2016, 47, 175-202.

16 Y. Yan, H. Xu, W. Guo, Q. L. Huang, M. B. Zheng, H. Pang and H. G. Xue, Inorg. Chem. Front., 2016, 3, 791-797.

17 F. Gao, J. Y. Qu, Z. B. Zhao, Z. Y. Wang and J. S. Qiu, Electrochim. Acta, 2016, 190, 1134-1141.

18 Y. Q. Zhao, M. Lu, P. Y. Tao, Y. J. Zhang, X. T. Gong, Z. Yang, G. Q. Zhang and H. L. Li, J. Power Sources, 2016, 307, 391-400.

19 W. Kiciński, M. Norek, A. Dziura and M. Polański, Microporous Mesoporous Mater., 2016, 225, 198-209.

20 M. M. Wan, X. D. Sun, Y. Y. Li, J. Zhou, Y. Wang and J. H. Zhu, ACS Appl. Mater. Interfaces, 2016, 8, 1252-1263.

21 L. L. Zhang, H. H. Li, Y. H. Shi, C. Y. Fan, X. L. Wu, H. F. Wang, H. Z. Sun and J. P. Zhang, ACS Appl. Mater. Interfaces, 2016, 8, 4233-4241.

22 W. Sun, S. M. Lipka, C. Swartz, D. Williams and F. Q. Yang, Carbon, 2016, 103, 181-192.

23 H. L. Wu, J. R. Mou, L. Zhou, Q. J. Zheng, N. Jiang and D. M. Lin, Electrochim. Acta, 2016, 212, 1021-1030. 
24 A. Bello, N. Manyala, F. Barzegar, A. A. Khaleed, D. Y. Momodu and J. K. Dangbegnon, RSC Adv., 2016, 6, 1800-1809.

25 S. T. Zhang, M. B. Zheng, Z. X. Lin, N. W. Li, Y. J. Liu, B. Zhao, H. Pang, J. M. Cao, P. He and Y. Shi, J. Mater. Chem. A, 2014, 2, 15889-15896.

26 S. Y. Bai, G. Q. Tan, X. Q. Li, Q. Zhao, Y. Meng, Y. J. Wang, Y. Z. Zhang and D. Xiao, Chem.-Asian J., 2016, 11, 1828-1836.

27 A. L. Cazetta, O. Pezoti, K. C. Bedin, T. L. Silva, A. P. Junior, T. Asefa and V. C. Almeida, ACS Sustainable Chem. Eng., 2016, 4, 1058-1068.

28 W. Chen, H. P. Yang, Y. Q. Chen, X. Chen, Y. Fang and H. Chen, J. Anal. Appl. Pyrolysis, 2016, 120, 186-193.

29 S. Nizamuddin, N. S. Jayakumar, J. N. Sahu, P. Ganesan, A. W. Bhutto and N. M. Mubarak, Korean J. Chem. Eng., 2015, 32, 1789-1797.

30 S. Nizamuddin, N. S. Jaya Kumar, J. N. Sahu, P. Ganesan, N. M. Mubarak and S. A. Mazari, Can. J. Chem. Eng., 2015, 93, 1916-1921.

31 S. Nizamuddin, N. M. Mubarak, M. Tiripathi, N. S. Jayakumar, J. N. Sahu and P. Ganesan, Fuel, 2016, 163, 88-97.

32 G. G. Choi, S. J. Oh, S. J. Lee and J. S. Kim, Bioresour. Technol., 2015, 178, 99-107.

33 A. Kundu, B. S. Gupta, M. A. Hashim and G. Redzwan, J. Cleaner Prod., 2015, 105, 420-427.

34 Z. Q. Ma, D. Y. Chen, J. Gu, B. F. Bao and Q. S. Zhang, Energy Convers. Manage., 2015, 89, 251-259.

35 J. R. García, U. Sedran, M. A. A. Zaini and Z. A. Zakaria, Environ. Sci. Pollut. Res., 2017, 1-10.
36 J. Y. Jeong, U. D. Lee, W. S. Chang and S. H. Jeong, Biosci. Rep., 2016, 219, 357-364.

37 K. S. Sulaiman, A. Mat and A. K. Arof, Ionics, 2016, 22, 911918.

38 M. Shoaib and H. M. Al-Swaidan, Hem. Ind., 2016, 70, 151157.

39 J. Yin, Y. Q. Zhu, X. Yue, L. Wang, H. Zhu and C. Y. Wang, Electrochim. Acta, 2016, 201, 96-105.

40 C. Laginhas, J. M. V. Nabais and M. M. Titirici, Microporous Mesoporous Mater., 2016, 226, 125-132.

41 Y. Q. Zhao, M. Lu, P. Y. Tao, Y. J. Zhang, X. T. Gong, Z. Yang, G. Q. Zhan and H. L. Li, J. Power Sources, 2016, 307, 391-400.

42 J. Li, K. Li, T. H. Zhang, S. Wang, Y. Jiang, Y. Bao and M. Y. Tie, Fibers Polym., 2016, 17, 880-887.

43 J. C. Wang and S. Kaskel, J. Mater. Chem., 2012, 22, 2371023725.

44 T. X. Shang and X. J. Jin, J. Solid State Electrochem., 2016, 20, 2029-2036.

45 P. Y. Wang, Q. L. Wang, G. H. Zhang, H. Y. Jiao, X. Y. Deng and L. W. Liu, J. Solid State Electrochem., 2016, 20, 319-325.

46 X. R. Li, S. Y. Ding, X. Xiao, J. Y. Shao, J. L. Wei, Y. Yu and H. Pang, J. Mater. Chem. A, 2017, 5, 12774-12781.

47 H. Cao, Z. Y. Chen, Q. L. Chen, C. Yang, L. R. Hou, M. Rehan, L. N. Tong and C. Z. Yuan, RSC Adv., 2016, 6, 81527-81533.

48 B. L. Xing, G. X. Huang, L. J. Chen, H. Guo, C. X. Zhang, W. Xie and Z. F. Chen, J. Porous Mater., 2016, 23, 67-73.

49 I. I. Misnon, N. K. M. Zain, R. A. Aziz, B. Vidyadharan and R. Jose, Electrochim. Acta, 2015, 174, 78-86.

50 T. Liang, C. L. Chen, X. Li and J. Zhang, Langmuir, 2016, 32, 8042-8049. 